\title{
Correction, Vol. 8, No. 12
}

In the article "Induction of Inflammation by West Nile virus Capsid through the Caspase-9 Apoptotic Pathway" by Joo-Sung Yang, et al., errors occurred in the Figure 5 caption on page 1384: delta symbols inadvertantly dropped or were replaced by the letter "d." The corrected caption appears below and online http://www.cdc.gov/ncidod/EID/vol8no12/02-0224-G5.htm.

Figure 5. Apoptosis determining domain in WNV-Cp gene. a, Schematic diagram of pcWNV-Cp-DJY, pcWNV-CpWT, and pcWNV$\mathrm{Cp} \Delta 3^{\prime}$ constructs. b, Immunoprecipitation of in vitro translated protein from pcWNV-Cp-DJY (Cp-DJY), pcWNV-CpWT (CpWT), and pcWNV$\mathrm{Cp}-3^{\prime}\left(\mathrm{Cp} \Delta 3^{\prime}\right)$ plasmids. As a negative control, pcDNA3.1 in vitro translated supernatants were analyzed. c , Colorimetric caspase-3 activity assay using pcWNV-Cp-DJY (Cp-DJY), pcWNV-CpWT (CpWT), or pcWNV-Cp 3'(Cp $\left.\Delta 3^{\prime}\right)$ plasmid-transfected cells. d, The cell lysates were assayed for caspase-9-like activity, and the pcDNA3.1-transfected cell lysate was used as the negative control. e, Inhibition of WNV-Cp-induced apoptosis by a dominant negative (DN) caspase-9 plasmid (DN Casp9) was assayed with equal amount of cell lysates from co-transfection of pcWNV-Cp-DJY (Cp-DJY) or pcWNV-CpWT (CpWT); an expression level of pro-caspase-9 cleavage products (35-37 kDa) was compared to 3'-terminal deletion mutant, pcWNV-Cp $\Delta 3^{\prime}\left(\mathrm{Cp} \Delta 3^{\prime}\right)$ and pcDNA3.1 by Western blot analysis with anti-human caspase-9 mAb.

\section{Correction Vol. 8, No. 12}

In the article, "Vector Competence of California Mosquitoes for West Nile virus" by Laura B. Goddard et al., errors occurred in the table on page 1387. The corrected table appears below and online at http://www.cdc.gov/ncidod/eid/vol8no12/02-0536.htm.

We regret any confusion these errors may have caused.

\begin{tabular}{|c|c|c|c|c|c|}
\hline Species & Source by county & $\begin{array}{c}\text { Day when transmission } \\
\text { was attempted }\end{array}$ & No. tested & Infection rate ${ }^{a}$ & $\begin{array}{c}\text { Transmission } \\
\text { rate }^{\mathrm{b}}\end{array}$ \\
\hline \multirow[t]{6}{*}{ Culex tarsalis } & Yolo & 7 & 30 & 87 & 60 \\
\hline & & 14 & 1 & 100 & 100 \\
\hline & Kern & 7 & 15 & 93 & 40 \\
\hline & & 14 & 35 & 74 & 60 \\
\hline & Riverside & 7 & 49 & 94 & 10 \\
\hline & & 14 & 55 & 85 & 62 \\
\hline \multirow[t]{5}{*}{ Cx. pipiens quinquefasciatus } & Kern & 7 & 50 & 86 & 4 \\
\hline & & 14 & 50 & 58 & 52 \\
\hline & Riverside & 7 & 60 & 8 & 0 \\
\hline & & 14 & 60 & 13 & 2 \\
\hline & Orange & 14 & 58 & 28 & 19 \\
\hline \multirow[t]{2}{*}{ Cx.p.pipiens } & Shasta & 7 & 45 & 80 & 9 \\
\hline & & 14 & 50 & 66 & 36 \\
\hline \multirow[t]{2}{*}{ Cx. stigmatosoma } & San Bernardino & 7 & 17 & 100 & 0 \\
\hline & & 14 & 31 & 100 & 71 \\
\hline \multirow[t]{4}{*}{ Cx. erythrothorax } & Orange & 7 & 15 & 67 & 0 \\
\hline & & 14 & 48 & 77 & 19 \\
\hline & Riverside & 7 & 15 & 100 & 33 \\
\hline & & 14 & 25 & 100 & 64 \\
\hline \multirow[t]{2}{*}{ Ochlerotatus dorsalis } & San Luis Obispo & 7 & 30 & 50 & 13 \\
\hline & & 14 & 29 & 41 & 34 \\
\hline \multirow[t]{2}{*}{ Oc. melanimon } & Kern & 7 & 50 & 46 & 18 \\
\hline & & 14 & 60 & 48 & 20 \\
\hline \multirow[t]{2}{*}{ Oc. sierrensis } & Lake & 7 & 40 & 5 & 3 \\
\hline & & 14 & 50 & 14 & 6 \\
\hline Aedes vexans & Riverside & 14 & 22 & 32 & 23 \\
\hline Culiseta inornata & Kern & 14 & 28 & 75 & 21 \\
\hline
\end{tabular}

${ }^{\mathrm{a}}$ Percent of mosquito bodies positive for WNV.

${ }^{\mathrm{b}}$ Percent of transmission attempts positive for WNV. 